Addressing weight stigma in physiotherapy: Development of a theory driven approach to rethinking weight related interactions.

Authors: Setchell $\mathrm{J}^{1,2}$, Gard $\mathrm{M}^{3}$, Jones $\mathrm{L}^{4}$ and Watson $\mathrm{BM}^{1}$

${ }^{1}$ School of Psychology, Faculty of Health and Behavioural Sciences, UQ, Brisbane

${ }^{2}$ School of Health and Rehabilitation Sciences, Faculty of Health and Behavioural Sciences, UQ, Brisbane, Australia

${ }^{3}$ School of Human Movement and Nutrition Sciences, Faculty of Health and Behavioural Sciences, UQ, Brisbane, Australia ${ }^{4}$ School of Applied Psychology, Griffith University, Brisbane, Australia Acknowledgements: A huge thank you to the participants for contributing their valuable time and energy to this project. Thank you also to Performance Rehab for providing the location for the group sessions. This project forms part of a PhD undertaken by the first author that is supported by a fellowship from the Fellowship Fund Inc of Graduate Women Queensland.

\title{
Declaration of interests:
}

The authors report no conflict of interest. 


\section{$\underline{\text { ABSTRACT }}$}

Weight stigma has been identified in physiotherapists in empirical investigations. However, there has been little consideration of how this stigma might be addressed. We propose a theory driven approach to developing interventions for reducing weight stigma in physiotherapy and discuss the design and exploratory trial of such an intervention. We highlight Goffman's work on stigma that provides social and embodied understandings of stigma. Goffman's approach however, is notably apolitical, ahistorical and lacks mechanisms for understanding power. We suggest post-structuralist perspectives can provide insight into these areas. Drawing on these theories we critically examine the literature on weight stigma reduction, finding that trials have largely been unsuccessful. We argue this may be due to overly passive and simplistic intervention designs. As context specific understandings are desirable, we examine the nature of physiotherapy to determine what might be relevant to rethinking weight in this profession. We then discuss the development of a multifactorial, active weight stigma intervention we trialed with eight physiotherapists. Supported by theory, the outcomes of the exploratory study suggest that physiotherapy specific factors such as fostering professional reflexivity and improving understandings of stigma need to be incorporated into an active intervention that considers the complex determinants of weight stigma. 


\section{INTRODUCTION AND OVERVIEW}

Weight stigma has been identified as an area of concern in physiotherapy (Setchell, Watson, Jones, and Gard, 2015a, 2015b; Setchell et al, 2014). In this paper we are interested in exploring ways to rethink weight related interactions in physiotherapy. We propose a theory driven approach to developing an intervention to reduce weight stigma and discuss the design and exploratory trial of this intervention. The paper is written in two sections. In the first section we explore relevant theory. Theory driven approaches allow for consideration of both the broad, conceptual principles that govern the production of stigma, as well as specific elements relevant in the physiotherapy context. We propose that it is helpful to draw from, and inter-relate, three bodies of literature to do this. The first is literature examining stigma broadly, exploring what stigma is, and how it is constituted and produced. We then examine weight stigma specifically, and apply stigma theory to critically examine weight stigma reduction interventions that have already been trialled. Finally, in the light of the theory we have discussed, we examine the context of the physiotherapy profession. Here we discuss particular factors endemic to this profession that might bring weight stigma into greater focus or salience. As a result, we highlight possible directions for a rethinking of weight related interactions in physiotherapy.

In the second section we outline our development of a weight stigma reduction intervention based on this theoretical exposé. While this development includes an empirical investigation of the intervention, the focus in this paper is a description of the process rather than being a 'trial of an intervention' per se. For this reason, the 'trial' is treated as exploratory, with points of interest presented, 
rather than a formal method and results. We conclude by considering the applicability of this theoretical and empirical research to physiotherapy.

\section{THEORETICAL EXPLORATION OF RETHINKING WEIGHT STIGMA}

In this section we discuss and draw together theory on stigma, weight stigma and physiotherapy to provide insight into possible options for (re)visioning physiotherapy interactions that involve body weight.

\section{$\underline{\text { Stigma }}$}

Much of the thinking about stigma in the last half century has been based on the seminal work of sociologist Erving Goffman (Link and Phelan, 2006). Through ethnographic explorations of mainly interpersonal interactions, Goffman described stigma as an "attribute that is deeply discrediting" (p. 13) that marks a spoilt identity (Goffman, 1963). He notes that when someone is stigmatised they are "reduced in our minds from a whole and usual person to a tainted, discounted one" (Goffman, 1963, p. 12). In this way stigma involves stereotypes, where a person is assumed to have (often negative) attributes on the basis of a stigmatised characteristic (Bos, Pryor, Reeder, and Stutterheim, 2013). These assumptions often lead to discrimination and may, at times dramatically, limit the life chances of the stigmatised person (Link and Phelan, 2006). Stigma, according to Goffman, should be seen as a social process, even if it is only directed at one person, as the person's individual characteristics matter less than the social markers of stigma (Brown, 2010). For the purposes of this paper the social context of interest is physiotherapy. 
Goffman focused closely on the embodied and 'felt' aspects of stigma (Hannem, 2012). He described, for example, the suicidal ideation of a young woman with facial disfigurement, the "anxious unanchoring" (p. 29) felt by someone with visible stigma anticipating social situations, and also the positive elements of a new perceptiveness that may come from experiencing stigma (Goffman, 1963). From his quotations from people who have experienced stigma, his readers can feel the fleshy presence of the stigmatised body. For example, Goffman (1963) outlined an experience of someone looking in the mirror after recovery from physical trauma: "It was there, it was there, it was real. Every one of these encounters [with himself in the mirror] was like a blow on the head" (p. 19). Thus, for Goffman, and many social psychologists and sociologists that refined and built on his work, stigma was an experience where bodies and feelings were important. Embodied elements of stigma seem relevant to explore in this paper, as bodies are integral to both fatness and physiotherapy (see below). As identified in the previous paragraph, Goffman also highlights that stigma is produced through social interaction, rather than residing within the stigmatised person or characteristic itself.

While approaches to stigma based on Goffman's work can explain some aspects of stigma, they lack mechanisms to understand the effects of broader social, political, cultural or historical variations on stigma. This has led to some authors suggesting that the concept of stigma should be abandoned (Oliver, 1992) or rethought (Farrugia, 2009; Hacking, 2011; Hannem, 2012). We agree with authors who have rethought stigma as a useful concept using a post-structural perspective to contextualise stigma. Prioritising a consideration of context is 
consistent with many other scholars in health and medicine who have turned to post-structuralist theorists to account for the political, cultural and historical dimensions of human experience in healthcare (Lupton, 2012b). However, few scholars have looked specifically at stigma in this way in a health context (Hacking and Farrugia are two notable exceptions). Investigating stigma associated with autism spectrum disorder, Farrugia (2009) demonstrated that a post-structuralist approach can complement Goffman's understandings of stigma, while Hacking (2011) discussed how post-structuralist approaches were insufficient without Goffman's applied approaches in discussing face-to-face clinical interactions.

The influential post-structuralist philosopher Michel Foucault considered behaviour, interactions and feelings to be produced through particular ways of thinking which he called discourses. He saw discourses as created not only by social context, as per Goffman, but also the political, cultural and historical context (Foucault, 1977a, 1978a). This view suggests that stigma is not finite or static but may be (re)constructed in varying environments (Tuffin, 2004). As Hannem (2012) suggests, post-structuralism provides insight into how stigma is produced or (re)created in different situations, and can provide opportunities to rethink the way we conceptualise people with stigmatised conditions. Later in this paper we apply these concepts to the topics of physiotherapy and weight stigma, and their intersection.

Goffman's approach also does not provide a way to understand the influence of power in stigma. Link and Phelan (2001), in line with post-structuralist thought, 
argue that "stigmatization is entirely contingent on access to social, economic and political power that allows the identification of differentness, the construction of stereotypes" (p. 367). Stigma is thus often associated with broader social inequities (Tuffin, 2004). As other authors have suggested, Foucault's broad theories on the production of truth, knowledge and power can be helpful to understand the power involved in stigma (Farrugia, 2009; Hacking, 2011; Hannem, 2012). In his work on governmentality, Foucault argued that power and governance (including governance of what is 'not normal') are exercised not only by the state and its institutions such as the army and police, but also in other institutions that are not traditionally seen as exercising power (Foucault, 1979). Foucault examined, for example, educational institutions, psychiatry and medicine (Foucault, 1977a, 1978a). In this paper, we apply this thinking to the institution of physiotherapy. Hannem (2012) discussed the relevance of Foucault's governmentality to stigma. She noted that stigma in an institutional setting comes from the institutionalisation of ways of managing the perceived risk of a stigmatised attribute. She argues that often the intent of the institution is overtly to help, yet "when the need for assistance is justified by the inherently "different," "risky" or "tainted" characteristics of the population, stigma is created in the very agencies that are supposed to be providing help" (Hannem, 2012, p. 25).

Foucault argued that the production of 'truth' is intimately linked with power (Foucault, 1977a). Institutions, including physiotherapy, produce truths about what is considered 'normal' (Nicholls and Gibson, 2010). Producing a 'normal' also necessarily creates an 'abnormal'. Defining 'abnormal' or 'deviant' attributes 
provides the conditions where attributes can become stigmatised as the 'spoiled' identities described by Goffman (Farrugia, 2009). Foucault described how people who are seen as abnormal are often 'disciplined' to become more 'normal' (Foucault, 1978b) P42-57. This discipline is an element of stigma.

Foucault used the concept of 'discipline' to talk about power that pervades many types of interactions, including the seemingly mundane. He theorised that people discipline themselves or others to become 'productive citizens' to support the 'greater good' of society (Foucault, 1978b) P42-57. Thus a person can be seen as unproductive or expensive if they are seen as having attributes or behaviours that may be costly to society. Such people can then be held individually accountable for this lack of productivity. If we apply Foucault's 'behaviour or conduct' to management of the body, the body can be seen as 'unproductive' or 'expensive'. As a result there may appear to be justification for 'disciplining' or exerting power over such a person to try to change them to be more 'productive'. In this way power is interwoven into some forms of stigma (disease, deformity, disability and weight stigmas are examples of this), where the stigmatised condition is seen as economic 'waste'. It is important to note, however, that this power moves in both directions; people who are stigmatised can resist against individuals or institutions (Foucault, 1977b).

To summarise, we have used aspects of dominant understandings of stigma, as outlined by Goffman, to identify that stigma is social and embodied. We have extended this theory using post-structuralist perspectives that provide an understanding of the involvement of power in stigma, where people/institutions 
produce 'truths' about what is 'normal' and employ 'disciplining' practices and beliefs to those considered 'not normal'. Furthermore, post-structuralist perspectives highlight that stigma is socially, politically and historically constructed. By extension then, stigma must invariably 'suit the times' and fit in well with hegemonic local and/or global beliefs, and is in fact created by them. As a result, to be stigmatising is, in some ways, to be a 'good citizen'. This means that stigma is likely to be difficult to change because it is supported and reinforced by much of society.

To reduce stigma, its fundamental causes must be addressed. This includes considering its production by socio-political-cultural contexts. For example, while the nature of 'successful' racism reduction interventions is far from uncontroversial, it is generally acknowledged that attempting to reduce racism requires complex and socially embedded interventions (e.g., see Paluck and Green, 2009). Similarly, health related stigma (such as that associated with HIV status) requires interventions that are multi-level and targeted at a number of elements of stigma (Heijnders and Van Der Meij, 2006). However, Goffman closes his seminal work on stigma by noting that while stigmas have commonalities, it is important to consider how they differ (Goffman, 1963). Link and Phelan (2001) also note that different conditions may be stigmatised in different ways. For example, the visibility and perceived controllability of the attribute affects the extent and form of discrimination (Hogg and Cooper, 2003). We turn now to explore weight stigma specifically, and the literature on reducing weight stigma.

\section{$\underline{\text { Weight stigma }}$}


Weight stigma, according to Goffman, is the discrediting of a person because they are seen as overweight or obese ${ }^{1}$. As noted in the previous section, poststructural perspectives highlight that weight stigma is socially, politically and historically situated and constructed. Power is also involved, as people may stigmatise others for being overweight by employing 'disciplining practices' in institutional and interpersonal contexts (Foucault, 1978b), because many people see weight as a controllable characteristic (Puhl and Heuer, 2009). Weight is also a highly visible characteristic making the embodied elements of stigma, highlighted by Goffman, salient. These aspects of weight stigma may have a certain relevance to the physiotherapy context, as discussed in the next section.

Weight stigma is not a new phenomenon, appearing numerous times in historical discourses (Gilman, 2008). However, these negative attitudes are relatively newly recreated and intensified in the current sociopolitical climate. There is now considerable literature that maps the pervasiveness (Puhl et al, 2015) and increasing prevalence (Andreyeva, Puhl, and Brownell, 2008; Tomiyama et al, 2015) of weight stigma across a number of cultural settings. While most studies have been conducted in developed countries, a smaller amount of literature has shown weight stigmatisation is becoming increasingly common globally (Brewis, Wutich, Falletta-Cowden, and Rodriguez-Soto, 2011). Weight stigma is more common towards women (Monaghan and Malson, 2013; Tiggemann and Rothblum, 1988; Wee et al, 2014), and intersects in particular ways with other stigmatised conditions such as race (Wee et al, 2014), and sexual preference

${ }^{1}$ There can be stigma associated with being seen as underweight but this has a different socio-political context and is not the focus of this paper. 
(McPhail and Bombak, 2014). Weight stigma has been documented extensively in the past decade in numerous health professionals including doctors, nurses, exercise scientists, and dieticians (Puhl and Heuer, 2009). Weight stigma has also been reported in physiotherapists (Sack et al, 2009; Setchell, Watson, Jones, and Gard, 2015a, 2015b; Setchell et al, 2014) and physiotherapy students (Awitudebe and Philips, 2009).

Post-structuralist perspectives, as outlined in the previous section on stigma, provide an opportunity to understand the socio-political reasons behind this current intensification of weight stigma, and may help provide some guidance as to how to reduce it. There are a number of potential explanations for the increase in weight stigma. For example, a number of authors have argued that one reason is increasing medicalisation, where attributes (including fatness) that were not previously considered 'an illness' become the subject of medical attention (Gard and Wright, 2005; Lupton, 2012a, 2012b; Murray, 2008). Here, as discussed in the previous section, the construction of 'truth' as relevant to stigma comes into play. Fatness has been constructed by medical discourses as abnormal. For example, Murray (2007) discusses medical constructions of fatness as 'deviance', and Tischner and Malson (2012) demonstrate that health approaches to 'obesity' often present fatness as 'failing'. Physiotherapy discourses also construct fatness in a similar way (see the next section), particularly in the context of the profession's increasing interest in public health.

Another likely prevailing political context behind the recent intensification of weight stigma is the global rise of moral agendas based on individualistic and 
economically rationalised ways of thinking (often called 'neoliberalism'). In neoliberal societies, individual responsibility and self-regulation (as opposed to institutional or governmental responsibility) are upheld as important moral imperatives (Foucault, 1979). Foucault's work on governmentality and biopolitics details how economic rationalism has been extended beyond its original application to politics and economics and is now often applied to all aspects of daily life (Foucault, 1979). When writing on the 'obesity epidemic', Wright and Harwood (2012) explain how governmentality "places individuals and populations under surveillance” (p. 2). This economic surveillance is frequently directed towards the fat body and can be seen in medical literature where, for example, the perceived financial costs are given as the rationale for reducing obesity in individuals or populations (Campos et al, 2006). Weight stigma (or the disciplining of fat bodies) is therefore the 'correct response' to the currently championed individualism, whereby people are increasingly seen as responsible for their own health and its presumed effect on societal wellbeing. As a result, people with so called 'lifestyle diseases' (i.e. what are seen as controllable diseases), including 'obesity', are constructed as failing because they are seen as making harmful choices (Guthman, 2009). This practice of economic rationalisation of bodies goes some way to explaining why the perceived controllability of weight mentioned above, is such a point of focus for those seeking to reduce weight stigma. In summary, prevailing political, social and cultural circumstances have produced an increased prevalence and an intensification of weight stigma. 
Given the current pervasiveness of weight stigma it is not surprising that a number of studies have been undertaken to try to reduce this form of stigma, many of them in a healthcare context. There is, as yet, no literature on this topic specific to physiotherapy. Weight stigma reduction researchers (understandably) focus interventions on what they believe to be the underlying cause of weight stigma. A systematic review by Daníelsdóttir, O'Brien, and Ciao (2010) found only 16 weight stigma intervention studies. These authors concluded that: "The lack of prejudice reduction following most interventions suggests that psychological mechanisms other than, or additional to, those being manipulated may underpin anti-fat prejudice" (p. 47), and called for more 'field based studies' to allow for assessment of 'real world efficacy' of attitude/behaviour changes. Since Daníelsdóttir and colleague’s study, one other review has been published. Lee, Ata, and Brannick (2014) conducted a metaanalysis of 29 weight stigma interventions. Interestingly, these authors found that researchers continued to focus on the same three main mechanisms that Daníelsdóttir and colleagues reported had little success in reducing weight stigma. These were controllability, empathy and social consensus. Researchers focusing on controllability set out to change the belief that fatness is caused by individually controllable factors (i.e., diet and exercise). Understandably, given Goffman's theories on the 'felt' and embodied nature of stigma, some interventions focused on improving empathy for fat people. The third main approach to stigma used the concept of social consensus, whereby researchers set up circumstances where people believed that the social consensus was that fat was not seen negatively in order to determine if this might reduce stigma. Some studies did focus outside of these three main mechanisms of weight 
stigma, looking at, for example, size acceptance training, positive or negative news reporting of fat bodies and cognitive dissonance-based interventions. Lee and colleague's results were remarkably similar to the earlier review, finding small significant effects and no notable difference between intervention types. In both systematic reviews, interventions were almost exclusively short term, such as one-off lab tests, single lectures or in-services, or web-based training.

We now discuss what we see as two main problems with most of these interventions. The first relates to the causes of stigma. The second relates to the strategies used to implement these interventions. Regarding the mechanisms or causes of stigma, we find it concerning that most of these studies investigated one main cause of weight stigma: an attempt to find a 'holy grail'. If we return to the theoretical understandings of stigma outlined earlier in this paper it is evident that stigmatising attitudes are likely to be considerably more complex. That is, if weight stigma is socially (historically, culturally, politically) embedded and created, it follows that stigma is part of a complex net of moral norms. As a result, changing weight stigma is unlikely to be simple. To recognise this, we suggest that it may be time to abandon the search for a main cause of weight stigma. Instead, it might be beneficial to create opportunities for a more complex integration of many or most causes of weight stigma. Using post-structuralist thinking we can recognise this multiplicity and, rather than creating an intervention that is structured around one singular cause of weight stigma, we can consider that all or most 'causes' are relevant. We then open up the possibility of using a variable combination of these factors in weight stigma interventions, depending on what is most relevant to the particular context. We 
could then address stigma as situated, as Foucault would see it, and as embodied and social, as Goffman would see it.

The second issue is that interventions to date have looked to a relatively narrow mode of delivery. Again, considering the complexity of weight stigma's integration with hegemonic moral norms, it seems unsurprising that these interventions have little lasting effect. Extensive literature on the difficulty of changing attitudes more broadly (Potter and Wetherell, 1987), as well as pedagogical theory (Giroux, 1988) also support this argument that a short, passive intervention is unlikely to have long term effects. Recent physiotherapy research also supports complex and embedded methods of learning (Patton, Higgs, and Smith, 2013). One of the interventions in Lee and colleague's 2014 meta-analysis used a complex set of causes, just as we advocate in the paragraph above. Yet the study was a one-off, passive intervention (viewing films) and had no sustained effect on weight stigma (Swift et al, 2012). Another study by Kushner, Zeiss, Feinglass, and Yelen (2014) delivered a more active intervention. Participants (medical students) read a paper on communication issues about weight and weight stigma, participated in a role-playing exercise followed by a facilitated reflection. Weight stigma was reduced in the short term but returned to normal after a year (Kushner, Zeiss, Feinglass, and Yelen, 2014). Therefore, while this was more involved than most weight stigma interventions, perhaps it was insufficiently prolonged or repeated.

In considering both of these issues with weight stigma interventions we can perhaps learn some lessons from the similarities between stigmatised conditions 
that Goffman highlighted (Goffman, 1963). We mentioned earlier that reduction of other types of stigma (such as racism, and HIV related stigma) required complex and embedded interventions. MacKean and GermAnn (2013) highlight this in their discussion of findings from an in-depth investigation of literature relevant to weight stigma reduction in healthcare: "Any approach to creating change must address the fundamental causes of stigma - that is, it must address the deeply held attitudes and beliefs of powerful groups that lead to stereotyping, setting apart, devaluating and discrimination, or it must change the circumstances so as to limit the power of such groups to make their views the dominant ones" (p. 5). As outlined in the previous section, while it is helpful to look at studies on other types of stigma reduction it is important to remember that in many ways stigmas are specific. For example, the 'immersion' and contact hypothesis type interventions that may work in some circumstances to reduce racism (Amir, 1969) seems to have the opposite effect on weight stigma (Alperin et al, 2014). So while we can learn some general concepts, such as the need for complexity and depth, from the reduction of other forms of stigma we also need to consider the nuances of weight stigma as outlined throughout this section.

Furthermore, as we argued earlier, stigma is situated and created socially, culturally and politically. It therefore follows that it is important to investigate the context in which one wishes to reduce that stigma. Expanding on the theory we have explored so far in this paper we now conclude this theoretical section by considering what might make weight stigma salient in a physiotherapy context.

\section{Physiotherapy and weight}


Empirical research has identified that physiotherapists have weight stigmatising attitudes (Sack et al, 2009; Setchell et al, 2014). This research has shown that physiotherapists tend to stereotype people who are overweight, with over $50 \%$ agreeing with statements about people who are overweight being sloppy, unattractive, weak willed, non-compliant and awkward (Sack et al, 2009). Research on physiotherapists' attitudes also indicates probable dislike and blame of people who are overweight, as well as a fear of becoming overweight themselves (Setchell et al, 2014). In these ways physiotherapists reproduce individualising and blaming discourses about weight similar to those held in the general population and in other health professions. However, knowing that physiotherapists have these attitudes does not necessarily help us to understand how they might play out in the particular context of physiotherapy. Some factors may make weight stigma particularly salient and consequential in physiotherapy. This may mean that to reduce weight stigma in physiotherapy it is likely to be beneficial to consider certain elements of the profession.

To state what might appear obvious, but is often overlooked, physiotherapy is inherently about the body (Nicholls and Gibson, 2010). Amongst other things, bodies are observed, touched, lifted, supported, measured and moved during physiotherapy. When considering the fleshy embodied nature of stigma as understood through Goffman, this factor in itself brings a certain salience to weight in physiotherapy contexts. For example, as patients of physiotherapists themselves have mentioned, rolls of fat might suddenly seem more obvious when the body is touched or observed in physiotherapy (Setchell, Watson, Jones, and Gard, 2015b). Of importance here is that physiotherapy comes from a largely 
positivist perspective that views the body biomechanically (i.e., like a machine), and the physiotherapist as a 'neutral observer'. Physiotherapists generally seek normalisation of the body, for example, its patterns of movement or joint range (Nicholls and Gibson, 2010). Power is relevant here, as this process establishes an ostensibly neutral 'expert status' of the physiotherapist and constructs a 'truth' that may not align with patients' perspectives (Eisenberg, 2012). Physiotherapists are also likely to apply this biomechanical, machine-like perspective to fatness as the profession increasingly considers elements of public health (Dean, 2009), including weight management (Snodgrass et al, 2014), to be part of its scope of practice. In keeping with weight stigmatising attitudes of blame outlined above, physiotherapists may 'discipline' the fat body with the objective of restoring a 'normality' that fits a biomechanical 'truth' such as simplistic diet versus exercise weight loss theories (Gard and Wright, 2005).

People seeking physiotherapy treatment consider the profession to be part of the health and fitness industries, both of which patients associate with negative attitudes towards weight (Setchell, Watson, Jones, and Gard, 2015b). Physiotherapists may inadvertently reinforce this belief by the use of images that privilege thin bodies, with visual displays of exercise equipment in their environments (Setchell, Watson, Jones, and Gard, 2015b) and possibly by disciplining their own bodies (Black et al, 2012; Dahl-Michelsen, 2014). Perhaps as a result of these factors, Setchell, Watson, Jones, and Gard (2015b) also found that patients expect and perceive that physiotherapists have negative attitudes towards 'overweight' bodies (weight stigma). The expectation of stigma means that patients might feel an "anxious unanchoring" (Goffman, 1963, p. 29) when 
coming into physiotherapy environments. This is of particular concern because another study shows that physiotherapists are often unaware of this potential discomfort of patients (Setchell, Watson, Jones, and Gard, 2015a). Here it may be relevant to note that the profession has been critiqued for lacking a tradition of reflexive understanding and analysis that would make stigma explicit and knowable (Clouder, 2000; Nicholls and Gibson, 2012; Trede, 2006). These findings highlight some specific considerations that may be important in a weight stigma intervention in the context of physiotherapy.

We now summarise the contribution of this theoretical section of the paper to considering how to reduce weight stigma in physiotherapy. Stigma involves embodied and social aspects and is complex and embedded (and created) in specific historical political and cultural settings. Weight stigma is pervasive and intricately embedded within current ways of thinking. There are many underlying mechanisms proposed to be creating a recent intensification of weight stigma. These include: perceiving weight as controllable, the medicalisation of fatness, social consensus, lack of empathy, and an economically rationalised 'disciplining' of the fat body. Interventions intended to reduce weight stigma have, to date, generally been unsuccessful. We propose that this lack of success may be due to insufficient consideration of the complexity of weight stigma. This is evident in the lack of multiplicity in the causes addressed in interventions and the simplicity of the methods of intervention. Physiotherapy is one environment where weight may be particularly salient and consequential due to the profession's focus on bodies, its biomechanical viewpoint, its role as part of the health and fitness industries, and its lack of reflexivity. In conclusion, 
we suggest active strategies are employed in order to reduce this type of stigma in physiotherapy and that the complex nature of the contributors to weight stigma require consideration. Furthermore, interventions must address the specific environment in which weight stigma is situated: in this case physiotherapy. In the following section we introduce a process we designed for encouraging a rethinking of weight in physiotherapy, based on these theoretical understandings.

\section{EMPIRICAL EXPLORATION OF RETHINKING WEIGHT STIGMA}

\section{$\underline{\text { Aims }}$}

We conducted an exploratory trial with eight physiotherapists based on action research principles. The purpose of the trial was to develop an intervention strategy that could incorporate the theoretical elements discussed in the first part of this paper. This process involved consideration of three broad aims. The first aim was to address the issue that weight stigma is unlikely to be reduced by trying to change only one causative factor. For this reason we designed the intervention to have sufficient time and flexibility to include relevant elements of both Goffman's and post-structuralist thinking on stigma. This meant the intervention was able to include embodied aspects of stigma (e.g. empathy, anticipation of potential discomfort), social aspects (e.g. communicating lack of judgment, understanding the impact of disrobing), and political-culturalhistorical aspects (e.g. understanding the political construction of weight, understanding how weight stigma might vary according to circumstance). The second aim was to address another issue we identified earlier- that weight stigma is unlikely to change with a simple mode of delivery such as a one-off or 
passive input. As a result we devised an intervention that involved a variety of ways of learning, with the majority of the process being active and applied. We also ensured that learning opportunities were repeated over time. The third aim was to recognize the importance of context in stigma. As a result this trial was situated within physiotherapy environments.

\section{Methodology}

We based the study design on the methodological approaches of action research. Like our trial, action research typically involves the researchers working with groups to facilitate changes through a participatory process that is grounded in experience (Kagan, Burton, and Siddiquee, 2008). This methodology does not necessarily employ a set method of data collection and often includes elements of techniques such as focus groups, narrative enquiry and semi-structured interviews (e.g., Siddiquee and Kagan, 2006), thus providing the flexibility that we required to introduce a number of active methods in the intervention. Action research is broadly grounded in social constructionist epistemology where the nature of reality is assumed to be multiple (Kagan, Burton, and Siddiquee, 2008). It is therefore suited to exploring an intervention underpinned by the constructionist theoretical approaches to stigma we have discussed in this paper (Chamberlain, 2014). An action research based approach was also appropriate for our study as it has often been employed by researchers who are interested in addressing stigma and discrimination (Gough and McFadden, 2013).

\section{Procedure}


This paper is not intended to be a traditional write up of the results of an empirical intervention study. We view this trial as an integral part of producing an intervention. That is, the intervention was not only developed a priori but was adapted and developed as the process was carried out. As is integral to action research approaches (Gough and McFadden, 2013), participant and researcher boundaries were not fixed. 'Participants' gave feedback on the process and had some input into the study design. As a result, the eight physiotherapists who participated in this study were important to the development and trial of this intervention. We provide information on their characteristics in Table 1. 'Participants' were all qualified clinicians, who replied to an email from the first author seeking physiotherapists interested in reflecting on their practice. Participants gave written informed consented to involvement in the study and were given debriefing information after study completion. The main facilitator of the process was the first author, who is thin, white, middle aged and an experienced clinical musculoskeletal physiotherapist. The third author provided reflexive feedback during the trial. Institutional ethics approval was gained and all data were handled confidentially within institutional guidelines, including the use of pseudonyms for exemplar quotes given below.

Insert Table 1 about here.

The study spanned approximately three months, with the most intensive phase completed in the first six weeks. The project was situated within physiotherapy in a number of ways: 1) by ensuring that participating physiotherapists carried out much of the intervention in their own individual work environments, 2) by 
conducting group sessions in a physiotherapy setting (a private practice), and 3) by encouraging reflexivity about the profession and about the participants as individual physiotherapists. Structurally, the study involved three main components: group discussion, individual learning and reflection, and one-toone discussions (see Figure 1 for a visual representation of the process). We present our rationale for the inclusion of these components under each subheading below. Although we will discuss each component separately, it is important to note that they occurred iteratively and sometimes overlapped (Figure 1).

Insert Figure 1 about here

\section{Group discussion}

Group discussions helped address all three aims of this intervention trial. They provided time (4-6hrs) to address the first aim of presenting many factors contributing to weight stigma. In keeping with the second aim, group discussions provided opportunities for active and dynamic forms of learning. We ran the sessions in an open plan section of a physiotherapy clinic amongst typical equipment such as plinths, strapping tape, and exercise apparatuses to help facilitate the third aim of keeping discussions contextualised. There were three opportunities for group discussions during this project, each two hours long and three weeks apart. We hoped that three weeks would provide sufficient time for participants to implement and reflect on changes in their work practices, yet not too much time to lose momentum. Participants could choose to have a one-toone reflection session by telephone with the facilitator instead of the third group 
session (depending on the time they had available and their personal preference). The facilitator used semi-structured questions (Appendix A) to prompt conversation about pre-reading of existing material about weight stigma. In the first session there were two papers discussed: one concerned the attitudes of physiotherapists towards fatness (Setchell et al, 2014), and the other physiotherapists' main ways of talking about weight (Setchell, Watson, Jones, and Gard, 2015a). The second session involved discussion of any changes in practice that the participants had implemented, or considered implementing, during the previous three weeks, and further reflections on the topics introduced in the first session. A third paper was introduced during this session about patients' experiences of weight stigma in physiotherapy (Setchell, Watson, Jones, and Gard, 2015b). The facilitator generally provided little input other than to facilitate discussion. Occasionally, she provided more input when participants required more prompting to consider a particular point (see the 'reflections on aims' section below for more detail on when extra input was needed). After the group discussions in both sessions, participants summarised the main points and used these points to facilitate individual reflection and planning (discussed below). Half of the participants chose a third group session with the others opting for one-to-one-phone calls (see below). No new literature was introduced for this final session, and discussion centered on changes to practice or new thoughts relevant to the research topic.

\section{Individual learning}

Individual learning was encouraged in three ways. First, as mentioned in the previous section, participants read and responded individually to the three 
papers on weight stigma in physiotherapy. Second, during the group sessions participants responded independently in written format to discussions to develop individual ideas. Here, they developed plans of how, if at all, they might change elements of their work practices. Finally, participants used a weekly diary for six weeks to reflect on their thoughts and feelings about the research topic, and to outline any changes they had made, or attempted, in their clinical practice. The diary included prompts that facilitated thinking on personal, interpersonal and institutional aspects of weight in physiotherapy. The three aims of this intervention were integrated into these individual components of the intervention. A range of causes of weight stigma were integrated into the reading materials and the application of learning to clinical practice facilitated by the reflexive diaries (aim one). The clinical practice component was an active, sustained and repeated component (aim two). Individual learning within each participant's work context meant participants had the opportunity to integrate their individual circumstances including their different work environments, personal and professional backgrounds (aim three).

\section{$\underline{\text { One-to-one discussions }}$}

This final component of the process took place by phone on one or two occasions with participants at the end of the project (Figure 1). In these sessions the facilitator and each participant discussed similar topics to those covered in the group sessions. Participants also had the opportunity to provide final feedback on the research process. One-to-one discussions had the benefit of confidentiality and individuality, and allowed participants who may not be as comfortable speaking within group environments another avenue for 
involvement. These conversations were semi-structured and provided a final platform where it was possible to incorporate elements of the aims of the intervention.

\section{REFLECTIONS ON AIMS - POINTS OF INTEREST}

In keeping with action research processes (Kagan, Burton, and Siddiquee, 2008) we outline points of interest that came out of this intervention study. We discuss these points in the light of the theory discussed earlier in this paper and the subsequent aims of the project. Critical reflections were derived from the reflexive field notes kept by the facilitator, the diaries of the participants, and audio recordings of the group and one-to-one discussions. Feedback from the participants and discussions between the researchers further contributed to this process. Because of the design and small sample size it was not possible to measure changes in attitudes or clinical behaviour. However, we can discuss what participants said about the study. Most participants spoke of notable changes as a result of participating in this study including differences in their attitudes towards people of size and their ways of working with larger patients. For example, they discussed changes in interactions with patients. Lenny said: "It certainly has allowed me to try and interact with my clientele on a different level". Another participant, Tracy, said: "I feel it's gone down really well because during the conversation [about weight] and afterwards as well, it's been a really good twoway conversation. [Patients'] body language has been open and happy and the eye contact has been excellent so I feel that it's been a positive thing that .... strengthened the therapist bond rather than scaring [patients] away." Participants also talked about gaining a deeper understanding of themselves. Helen said: "I 
really think [participating in the study] has been beneficial. Exploring different parts of my conscious or subconscious that I wasn't aware of'. One participant said that, while she enjoyed interacting with the subject matter, little had changed in her practice. Perhaps this was because this participant self-identified as being overweight, so had lived understanding of this type of stigma. It would be valuable to explore in further research how (and if) this type of process might be made more relevant for those who have lived experience of weight stigma themselves.

The trial process met the first aim developed from the theoretical exploration of weight stigma in physiotherapy. This aim was to provide time and flexibility to explore many aspects of weight stigma derived from Goffman's and poststructuralist thinking on the topic. This included the 'big three causes' focused on in previous weight stigma reduction research (controllability, empathy and social consensus), as well as other elements of embodied, social, political and historical contributors. These topics were introduced in a number of ways: through the papers, by the facilitator, or by the participants themselves. During the trial, the facilitator - and to some extent the participants - could tailor the depth of exploration, and points could be reintroduced or reiterated as required. Whether this exploration was sufficiently comprehensive to change attitudes or practices could be the subject of future investigations.

The second aim was to create an intervention that involved active forms of learning that were repeated over time. Active learning was required in all aspects of the study design including: the reflexive diaries, interaction with the 
reading material, group discussions, one-to-one sessions and integration into the work environment through planning and doing. Although some input was given by the facilitator and provided in the reading material, the participants' experiences and contexts were integral to, and directive of the content in the intervention. There were many opportunities for repetition and re-iteration built into the study (see Figure 1). Again, whether this active learning was dynamic or sustained enough to change practice or attitudes would be interesting to explore further in future studies.

Finally, in addressing the third aim of the project the design was congruent with the theory discussed earlier in the paper regarding the importance of situating stigma, including calls by the systematic reviews of Daníelsdóttir, O'Brien, and Ciao (2010) and Lee, Ata, and Brannick (2014) for more field based studies. A number of points of interest were specific to the context of physiotherapy and are outlined in the remainder of this section. The content and design of the study were directly relevant to physiotherapy and could be adapted to suit participants' individual work environments. The trial design was flexible enough that it could be, in many ways, moulded by the participants themselves. Participants were able to make their own choices about what to do with their new learning and take into account a number of factors that make each situation different.

While it is not possible to determine exactly what happened in clinical situations, participants were encouraged to adapt learning to their own personalities, their body, their gender, their work environment, and the variety of patients they 
might see. Xander described a change in an understanding of himself in his professional role and a greater understanding of the role of bodies in physiotherapy. He said:

"The other thing that I have been more aware of is as a professional, we are desensitised to other people's bodies. We see them all the time. Every half an hour I see somebody's body. For me, I don't mind if they are tall, short, big, small. I don't think about it but obviously the patient themselves, if they have a poor body image - self-image, they may be more sensitive about it. So I need to kind of put myself into their shoes"

There was an interesting interaction that occurred when physiotherapists started to reassess their status as an objective, neutral observer. Nathaniel said: "Well, I thought of myself as being fairly neutral....But now, actually, I realise that that's not enough. You know, having a neutral feeling that is not enough". Some participants described approaching patients differently including addressing weight in an indirect, gentle and tentative manner. This caused some conflict for physiotherapists as it contrasted with physiotherapy's positivist, 'body as a machine' approach outlined earlier in this paper. For example, Xander discussed the discomfort he felt in an interaction where he used an indirect, cautious approach to refer a patient to a dietician: "I perceived my interaction as awkward and clumsy rather than being as smooth as it could have been". In contrast, he said that the patient felt comfortable during the exchange: "She didn't feel awkward at all, she was fine, she was completely fine and happy. It was more me". This change 
in approach goes against physiotherapists' traditional 'neutral expert status' approach to interactions with patients.

Congruent with critiques of physiotherapy for lacking reflexivity outlined earlier in this paper, the facilitator noted the participants' unfamiliarity with theoretical, philosophical and psychological concepts. As a result it was important to allow opportunities to explain these concepts as they arose. There were many opportunities for reflection and reflexivity, both formally in the diaries, the oneto-one sessions and also, at times, in the group discussions. Despite the inclusion of this element, the participants seemed to find it particularly challenging to reflect about possible effects of their own body on interactions with patients, and how patients might perceive the profession and themselves as individual physiotherapists. The participants tended to view their own bodies as irrelevant in interactions with patients, and found it difficult to consider how their own body size and presentation (Butler, 1999) might affect weight related interactions with patients (Setchell, Watson, Jones, and Gard, 2015b). This was particularly the case when the physiotherapist was thin or muscular or did not self-identify as overweight at that time. This highlights the need for time and emphasis on reflexivity in rethinking weight in physiotherapy. Helen said: "I just felt that thinking about it all and reflecting just took time, took a lot of thought, because it's not things, honestly, that I have really spent time to reflect on before." Tracy discussed a new ability to reflect on a number of elements of her practice:

"I've been a bit more aware of how patients might be looking at, like, me and at our reception staff and our advertising material and our website and thinking of what 
we project by what we look like and how we appear. So I've never really thought of it from that point of view. So that's got me thinking about how we do things and how we present and thinking what people might be wondering about us".

This new level of reflexivity was evident on a number of occasions when participants talked about applying the learning they experienced in this trial to other types of stigma, not only that associated with fatness. This was evidence of integration of learning (Barber, 2012). Tracy, for example, talked about how she had a new comfort with other stigmatised conditions such as mental health. She gave the example of an interaction with a suicidal patient that she had not previously felt able to address: "things that [were] in the too hard basket [previously]. [I thought] I might just stick to muscles and joints. Things that I might have just glossed over and moved onto something more in my comfort zone, [now] I'm more happy to address that then and there."

In summary, the trial was successful in addressing its aims and aligned with theory about weight stigma and physiotherapy. The trial included multifactorial elements of possible contributors to weight stigma and employed an active and prolonged approach. The intervention was specific to the physiotherapy context and provided participants with opportunities to reflexively address salient elements of their professional practice. Although the study design did not allow for direct assessment of attitude or behaviour change, participants spoke of changes that aligned with a rethinking of their way of working with weight in their professional roles. 


\section{CONCLUSION}

In this paper we explored how to approach reducing weight stigma in physiotherapy. We developed a relevant theoretical understanding of stigma by integrating elements of Goffman's seminal work with post-structuralist perspectives based on the theories of Foucault. We highlighted how Goffman's work helps gain an understanding of the embodied and social aspects of stigma that are likely to be involved in weight related interactions in physiotherapy. Furthermore, we demonstrated how a post-structuralist approach helps to uncover and address broader contextual cultural and political aspects of such interactions. Using this integrated understanding of stigma we highlighted weight stigma as a complex, socially embedded (and produced) phenomenon. We employed this theoretical understanding to (re)consider how to reduce weight stigma. We found that most weight stigma reduction interventions have been largely unsuccessful, and have often employed simplistic and short-term interventions. We argued that simple approaches to changing weight stigmatising attitudes are insufficient if we consider that by countering stigma we are trying to address underlying complex and socially embedded issues. We designed and piloted a process that applied these theoretical concepts in the context of physiotherapy. The exploratory intervention involved integration of many contributors to weight stigma, active learning (via group and one-to-one sessions, reflexive diaries) and interactions with reading materials. Physiotherapy specific considerations included providing time to develop skills and knowledge about reflexivity, reconsidering the physiotherapist as a 'neutral observer' and an 'expert', and a greater awareness of the influence of bodies in this professional context. The intervention had flexibility and could feasibly be 
adapted for integration into undergraduate, postgraduate and professional development education. This paper provides new possibilities for reconceptualising the fat body and creates openings for rethinking weight interactions in physiotherapy and beyond. 


\section{$\underline{\text { Reference list }}$}

Alperin A, Hornsey MJ, Hayward LE, Diedrichs PC, Barlow FK 2014 Applying the contact hypothesis to anti-fat attitudes: Contact with overweight people is related to how we interact with our bodies and those of others. Social Science \& Medicine, 123C: 37-44. doi: 10.1016/j.socscimed.2014.10.051

Amir Y 1969 Contact hypothesis in ethnic relations. Psychological Bulletin, 71: 319-342.

Andreyeva T, Puhl RM, Brownell KD 2008 Changes in perceived weight discrimination among Americans, 1995-1996 through 2004-2006. Obesity, 16: 1129-1134. doi: 10.1038/oby.2008.35

Awitudebe A, Philips J 2009 Knowledge and attitudes of physiotherapy students towards obesity. South African Journal of Physiotherapy, 65: 27-31.

Barber JP 2012 Integration of learning: A grounded theory analysis of college students' learning. American Educational Research Journal, 49: 590-617. doi: 10.3102/0002831212437854

Black B, Marcoux BC, Stiller C, Qu XG, Gellish R 2012 Personal health behaviors and role-modeling attitudes of physical therapists and physical therapist students: A cross-sectional study. Physical Therapy, 92: 1419-1436. doi: 10.2522/ptj.20110037

Bos A, Pryor J, Reeder G, Stutterheim S 2013 Stigma: Advances in theory and research. Basic and Applied Social Psychology, 35: 1-9. doi: 10.1080/01973533.2012.746147

Brewis A, Wutich A, Falletta-Cowden A, Rodriguez-Soto I 2011 Body norms and fats stigma in global perspective. Current Anthropology, 52. doi: 10.1086/

Brown R 2010 Prejudice: It's social psychology. (2nd edn). Hoboken, NJ, John Wiley \& Sons.

Butler J 1999 Gender trouble. Milton Park, UK, Routledge.

Campos P, Saguy A, Ernsberger P, Oliver E, Gaesser G 2006 The epidemiology of overweight and obesity: Public health crisis or moral panic? International Journal of Epidemiology, 35: 55-60. doi: 10.1093/ije/dyi254

Chamberlain K 2014 Epistemology and qualitative research. In P Rohleder \& A Lyons (eds), Qualitative research in clinical and health psychology. London, UK, Sage.

Clouder L 2000 Reflective practice in physiotherapy education: A critical conversation. Studies in Higher Education, 25: 211-223.

Dahl-Michelsen T 2014 Sportiness and masculinities among female and male physiotherapy students. Physiotherapy Theory and Practice, 30: 329-337. doi: 10.3109/09593985.2013.876692

Daníelsdóttir S, O'Brien K, Ciao A 2010 Anti-fat prejudice reduction: A review of published studies. Obesity Facts, 3: 47-58. doi: 10.1159/000277067

Dean E 2009 Physical therapy in the 21st century (part I): Toward practice informed by epidemiology and the crisis of lifestyle conditions. Physiotherapy Theory and Practice, 25: 330-353.

Eisenberg NR 2012 Post-structural conceptualizations of power relationships in physiotherapy. Physiotherapy Theory and Practice, 28: 439-446. doi: 10.3109/09593985.2012.692585 
Farrugia D 2009 Exploring stigma: Medical knowledge and the stigmatisation of parents of children diagnosed with autism spectrum disorder. Sociology of Health and Illness, 31: 1011-1027. doi: 10.1111/j.14679566.2009.01174.x

Foucault M 1977a Discipline and punish: The birth of the prison. London, UK, Allen Lane.

Foucault M 1977b The end of the monarchy of sex, Trans: Dudley M. Marchi, in Foucault live (interviews, 1961-1984). This interview first appeared in Le Nouvel Observateur, 12-21 March

Foucault M 1978a The history of sexuality (Vol. Volume 1: An introduction). London, UK, Penguin.

Foucault M 1978b Security, territory, population: Lectures at the Collège de France 1977-1978, New York, Palgrave Macmillan

Foucault M 1979 The birth of biopolitics: Lectures at the College de France 19781979. New York, Palgrave Macmillan.

Gard M, Wright J 2005 The obesity epidemic: Science, morality and ideology. London, UK, Routledge.

Gilman SL 2008 Fat: A cultural history of obesity. Cambridge, UK, Polity Press.

Giroux H 1988 Teachers as intellectuals: Toward a critical pedagogy of learning. . Westport, CT, Greenwood Publishing Group.

Goffman E 1963 Stigma: Notes on the management of spoiled identity. London, UK, Penguin.

Gough B, McFadden M 2013 Critical social psychology (2nd edn). New York, NY, Palgrave Macmillan.

Guthman J 2009 Teaching the politics of obesity: Insights into neoliberal embodiment and contemporary biopolitics. Antipode, 41: 1110-1133. doi: 10.1111/j.1467-8330.2009.00707.x

Hacking I 2011 Between Michel Foucault and Erving Goffman: Between discourse in the abstract and face-to-face interaction. Economy and Society, 33: 277-302. doi: 10.1080/0308514042000225671

Hannem S 2012 Theorizing stigma and the politics of resistance. In S Hannem \& C Bruckert (eds), Stigma revisited. Ottawa, University of Ottowa Press.

Heijnders M, Van Der Meij S 2006 The fight against stigma: An overview of stigma-reduction strategies and interventions. Psychology, Health \& Medicine, 11: 353-363. doi: 10.1080/13548500600595327

Hogg MA, Cooper J 2003 The sage handbook of social psychology. London, UK, Sage.

Kagan C, Burton M, Siddiquee A 2008 Action research. In C Willig \& W StaintonRogers (eds), The sage handbook of qualitative research. London, Sage.

Kushner RF, Zeiss DM, Feinglass JM, Yelen M 2014 An obesity educational intervention for medical students addressing weight bias and communication skills using standardized patients. BMC Medical Education, 14: 1-8. doi: 10.1186/1472-6920-14-53

Lee M, Ata RN, Brannick MT 2014 Malleability of weight-biased attitudes and beliefs: A meta-analysis of weight bias reduction interventions. Body Image, 11: 251-259. doi: 10.1016/j.bodyim.2014.03.003

Link B, Phelan J 2001 Conceptualizing stigma. Annual Review Sociology, 27: 363385. 
Link B, Phelan J 2006 Stigma and its public health implications. The Lancet, 367: 528-529. doi: 10.1016/S0140-6736(06)68184-1

Lupton D 2012a Fat. New York, NY, Routledge.

Lupton D 2012b Medicine as culture: Illness, disease and the body (3rd edn). London, UK, Sage.

MacKean G, GermAnn K. (2013). Reducing weight bias and stigma in British Columbia's health care system: Findings from a critical review of the literature and environment scan.

McPhail D, Bombak AE 2014 Fat, queer and sick? A critical analysis of 'lesbian obesity' in public health discourse. Critical Public Health, 25: 539-553. doi: 10.1080/09581596.2014.992391

Monaghan LF, Malson H 2013 'It's worse for women and girls': Negotiating embodied masculinities through weight-related talk. Critical Public Health, 23: 304-319.

Murray S 2007 Corporeal knowledges and deviant bodies: Perceiving the fat body. Social Semiotics, 17: 361-373. doi: 10.1080/10350330701448694

Murray S 2008 Pathologizing 'fatness': Medical authority and popular culture. Sociology of Sport Journal, 25: 7-21.

Nicholls DA, Gibson BE 2010 The body and physiotherapy. Physiotherapy Theory and Practice, 26: 497-509. doi: 10.3109/09593981003710316

Nicholls DA, Gibson BE 2012 Editorial: Philosophy and physiotherapy. Physiotherapy Theory and Practice, 28.

Oliver M 1992 The politics of disablement. Basingstoke, UK., Macmillan.

Paluck EL, Green DP 2009 Prejudice reduction: What works? A review and assessment of research and practice. Annual Review of Psychology, 60: 339-367. doi: 10.1146/annurev.psych.60.110707.163607

Patton N, Higgs J, Smith M 2013 Using theories of learning in workplaces to enhance physiotherapy clinical education. Physiotherapy Theory and Practice, 29: 493-503. doi: 10.3109/09593985.2012.753651

Potter J, Wetherell M 1987 Discourse and social psychology: Beyond attitudes and behaviour. London, Sage.

Puhl RM, Heuer CA 2009 The stigma of obesity: A review and update. Obesity, 17: 941-964. doi: 10.1038/oby.2008.636

Puhl RM, Latner JD, O'Brien K, Luedicke J, Daníelsdóttir S, Forhan M 2015 A multinational examination of weight bias: Predictors of anti-fat attitudes across four countries. International Journal of Obesity. doi: 10.1038/ijo.2015.32

Sack S, Radler D, Mairella K, Touger-Decker R, Khan H 2009 Physical therapists' attitudes, knowledge, and practice approaches regarding people who are obese. Phys Ther, 89: 804-815.

Setchell J, Watson BM, Jones L, Gard M 2015a Physical therapists' ways of talking about overweight and obesity: Clinical implications. Physical Therapy, Forthcoming.

Setchell J, Watson BM, Jones L, Gard M 2015b Weight stigma in physiotherapy practice: Insights from patient perceptions of interactions with physiotherapists. Manual Therapy, In Press.

Setchell J, Watson BM, Jones L, Gard M, Briffa K 2014 Physiotherapists demonstrate weight stigma: A cross-sectional survey of australian 
physiotherapists. Journal of Physiotherapy, 60: 157-162. doi: http://dx.doi.org/10.1016/j.jphys.2014.06.020

Siddiquee A, Kagan C 2006 The internet, empowerment, and identity: An exploration of participation by refugee women in a community internet project (CIP) in the united kingdom (UK). Journal of Community \& Applied Social Psychology, 16: 189-206. doi: 10.1002/casp.855

Snodgrass SJ, Carter AE, Guest M, Collins CE, James C, Kable AK, ... Plotnikoff RC 2014 Weight management including dietary and physical activity advice provided by australian physiotherapists: A pilot cross-sectional survey. Physiotherapy Theory and Practice, 30: 409-420. doi: 10.3109/09593985.2013.877112

Swift J, Tischler V, Markham S, Gunning I, Glazebrook C, Beer C, Puhl RM 2012 Are anti-stigma films a useful strategy for reducing weight bias among trainee healthcare professionals? Results of a pilot randomized control trial. Obesity Facts, 6: 91-102. doi: 10.1159/000348714

Tiggemann M, Rothblum E 1988 Gender differences in social consequences of perceived overweight in the united states and australia. Sex Roles, 18: 7586. doi: $10.1007 /$ BF00288018

Tischner I, Malson H 2012 Deconstructing health and the un/healthy fat woman. Journal of Community \& Applied Social Psychology, 22: 50-62. doi: 10.1002/casp.1096

Tomiyama AJ, Finch LE, Belsky AC, Buss J, Finley C, Schwartz MB, Daubenmier J 2015 Weight bias in 2001 versus 2013: Contradictory attitudes among obesity researchers and health professionals. Obesity (Silver Spring), 23: 46-53. doi: $10.1002 /$ oby. 20910

Trede F. (2006). A critical practice model for physiotherapy. (Doctoral Dissertation, The University of Sydney, Sydney, Australia). Retrieved from http://eresearch.qmu.ac.uk/1722/1/eResearch_1722.pdf

Tuffin K 2004 Understanding critical social psychology. London, UK, Sage.

Wee CC, Davis RB, Chiodi S, Huskey KW, Hamel MB 2014 Sex, race, and the adverse effects of social stigma vs. Other quality of life factors among primary care patients with moderate to severe obesity. Journal of General Internal Medicine. doi: 10.1007/s11606-014-3041-4

Wright J, Harwood V 2012 Biopolitics and the 'obesity epidemic' (1st edn). Hoboken, Taylor and Francis. 